\title{
Pinhole-Free Shell-Isolated Nanoparticle Enhanced Raman Spectroscopy for Interference-Free Probing of Electrochemical Reactions
}

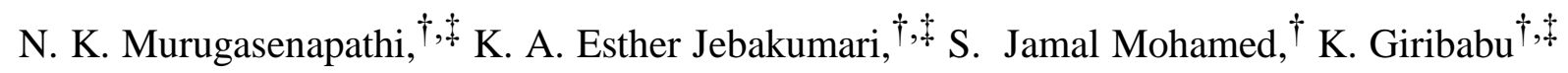
Tamilarasan Palanisamy, ${ }^{*}, \dagger,+$

${ }^{\dagger}$ Electrodics and Electrocatalysis Division (EEC), CSIR-Central Electrochemical Research Institute (CECRI), Karaikudi 630003. Tamilnadu. India.

$\$$ Academy of Scientific and Innovative Research (AcSIR), CSIR-Central Electrochemical Research Institute (CECRI) Campus, Karaikudi 630003. Tamil Nadu. India.

*Corresponding author; Email: tamilan@ cecri.res.in.

ESI 1: Redox reaction of Nile Blue A
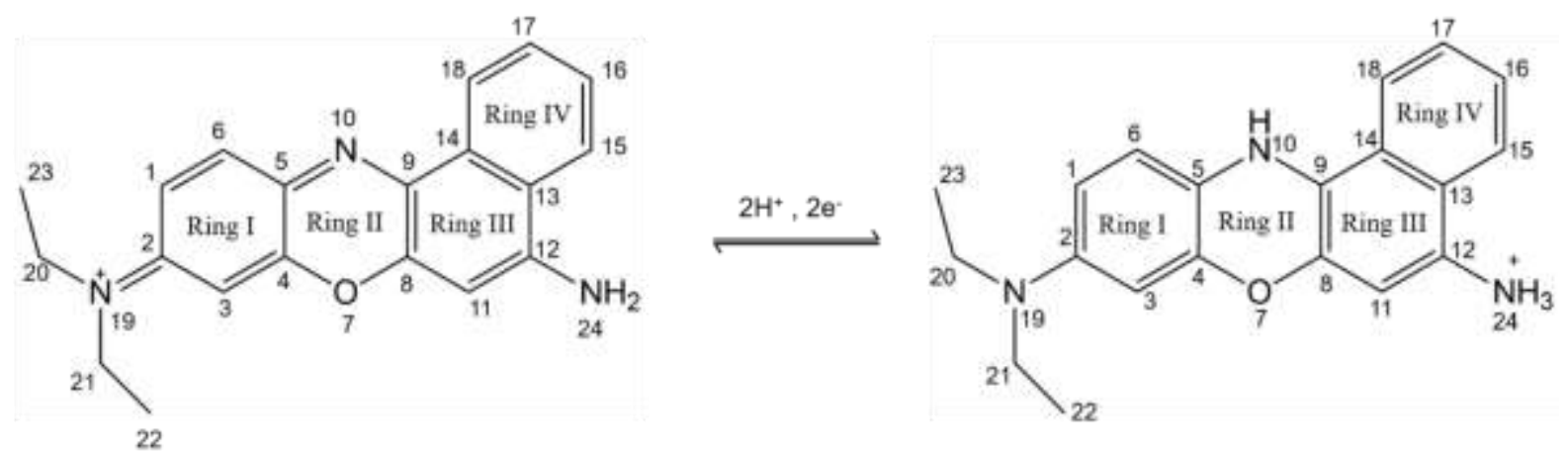

Figure S1. Redox mechanism of Nile Blue A in pH 6. 
Nile Blue A was chosen as a model molecule and its redox reaction on glassy carbon is analyzed in this study. The molecular structure is reproduced from the previous report ${ }^{1}$. As a class of phenoxazine dye, Nile Blue A has been used extensively in several $\mathrm{pH}$ dependent electrochemical reactions. Cotton et al. reported that the redox mechanism of NBA on Ag merely depend on $\mathrm{pH}^{2}$. At low $\mathrm{pH}$ regime $(\mathrm{pH}<6)$ two proton, two electron involves in the process, whereas two electron and one proton takes place at high $\mathrm{pH}$ value $(\mathrm{pH}>6)$. Under our experimental conditions $(\mathrm{pH}=6)$, it is believed that the NBA follows a $2 \mathrm{H}^{+}+2 \mathrm{e}^{-}$redox mechanism.

\section{ESI 2: Experimental section}

\subsection{Materials and Equipments}

Silver nitrate $\left(\mathrm{AgNO}_{3}\right)$, sodium borohydride $\left(\mathrm{NaBH}_{4}\right)$, tetraethylorthosilicate (TEOS), cetyltrimethylammonium bromide (CTAB), (3-Aminopropyl)triethoxysilane (APTES) and Nile Blue A perchlorate dye were purchased from Sigma Aldrich. All the reagents were used as received without further purification. All aqueous solutions and electrolytes were prepared using deionised water (resistivity of $18.2 \mathrm{M} \Omega \mathrm{cm}$ ). Glassy carbon electrodes (GCE) (3 mm dia.) were purchased from $\mathrm{CH}$ Instruments, Inc., USA and used after physical polishing. Glasswares were cleaned using aqua regia and piranha solutions followed by ultrasonic cleaning and dried in a hot air oven after thoroughly rinsed with deionized water.

The in-situ EC-SERS analysis was carried out using a Renishaw inVia confocal microprobe Raman spectrometer equipped with air-cooled CCD, 20x magnification objective lens and a 1200 grooves $/ \mathrm{mm}$ grating. The $785 \mathrm{~nm}$ diode laser with $2.5 \mathrm{~mW}$ power and exposure time with the sample was $30 \mathrm{~s}$ was used invariably unless otherwise mentioned. A Biologic SP300 electrochemical workstation was used for all the electrochemical measurements. The optical absorption spectrum of the nanostructures was acquired by a PerkinElmer lambda 650 
spectrophotometer. High resolution transmission electron micrographs (HR-TEM) were recorded using FEI TalosF200S, operating at $200 \mathrm{kV}$ while a Carl Zeiss (Germany) SUPRA 55VP, Gemini Column, operating at $15 \mathrm{kV}$, was used for field emission scanning electron micrographs (FESEM).

\subsection{Synthesis of silver nanoparticles and $\mathrm{Ag} @ \mathrm{SiO}_{2}$ nanostructures}

Silver nanoparticles (Ag NPs) were synthesized adopting a procedure reported elsewhere ${ }^{3}$. In a typical reaction, $30 \mathrm{ml}$ of $4 \mathrm{mM} \mathrm{NaBH}_{4}$ solution in deionized water was cooled in an ice bath for 30 min followed by the drop-wise addition of $20 \mathrm{~mL}$ of $2 \mathrm{mM} \mathrm{AgNO}_{3}$ aqueous solution under vigorous stirring. The formation of silver nanoparticles has been confirmed by the change in color of the solution to light yellow.

$\mathrm{Ag} @ \mathrm{SiO}_{2}$ core shell nanoparticles were synthesized with a slight modification of previous report ${ }^{4}$. Briefly, $450 \mu \mathrm{l}$ solution of $0.5 \mathrm{M} \mathrm{CTAB}$ was added to the prepared Ag NPs dispersion and the stirring was continued for 6 hours for thorough surface capping. Then $\mathrm{pH}$ of this solution was adjusted to 10 by adding $0.1 \mathrm{M} \mathrm{NaOH}$ aqueous solution. $5 \mathrm{ml}$ of 2.94 $\mathrm{mM}$ APTES was added drop-wise into the solution with vigorous stirring for $30 \mathrm{~min}$ to ensure the monolayer of linkers. Subsequently, $27.9 \mu 1$ of TEOS $(2.75 \mathrm{mM})$ was added to the solution and stirred for another $12 \mathrm{~h}$ at room temperature for thorough coverage of the silver surface. The nanostructures were separated by centrifugal force $(\mathrm{RCF}=4700 \mathrm{~g})$ and washed twice with deionized water. The concentrated shell-isolated nanoparticles were stored in an opaque container at $4{ }^{\circ} \mathrm{C}$ for future use.

\subsection{Preparation of SERS and SHINERS electrodes}

Prior to each experiment, the GCE was cleaned by a course of physical polishing using alumina powders $(1,0.3$ and $0.05 \mu \mathrm{m}$, respectively) followed by mild ultrasonic $(70 \mathrm{~W})$ 
cleaning for 5 min in deionised water. The "SERS electrode" was prepared by drop-casting a thin layer of freshly prepared Ag NPs on GCE, while the concentrated $\mathrm{Ag} @ \mathrm{SiO}_{2}$ dispersion was used for the "SHINERS electrode". The drop-casted electrodes were dried under a dynamic vacuum and stored in a vacuum desiccator. Prior to the spectroelectrochemical analysis, the electrodes were incubated in $1 \mathrm{mM}$ aqueous solution of NBA for $10 \mathrm{mins}$ at room temperature. Then the excess NBA molecules were rinsed out by dipping the electrode in deionized water.

\section{ESI 3: Spectroelectrochemical cell analysis}

An indigenous three-electrode spectroelectrochemical cell (Figure S2) was used for the insitu Raman studies, where nanostructure-modified NBA-incubated GC electrode (dia $3 \mathrm{~mm}$ ), saturated $\mathrm{Ag} / \mathrm{AgCl}$ electrode and a large Pt wire were used as working, reference and counter electrodes, respectively. Here, $0.2 \mathrm{M}$ phosphate buffer solution ( $\mathrm{pH}$ 6) was used as an electrolyte. The electrochemical and spectral data were correlated in the time domain. A similar three-electrode configuration was used with $0.5 \mathrm{M} \mathrm{H}_{2} \mathrm{SO}_{4}$ electrolyte to confirm the quality of the silica shell in $\mathrm{Ag} @ \mathrm{SiO}_{2}$ nanostructure.
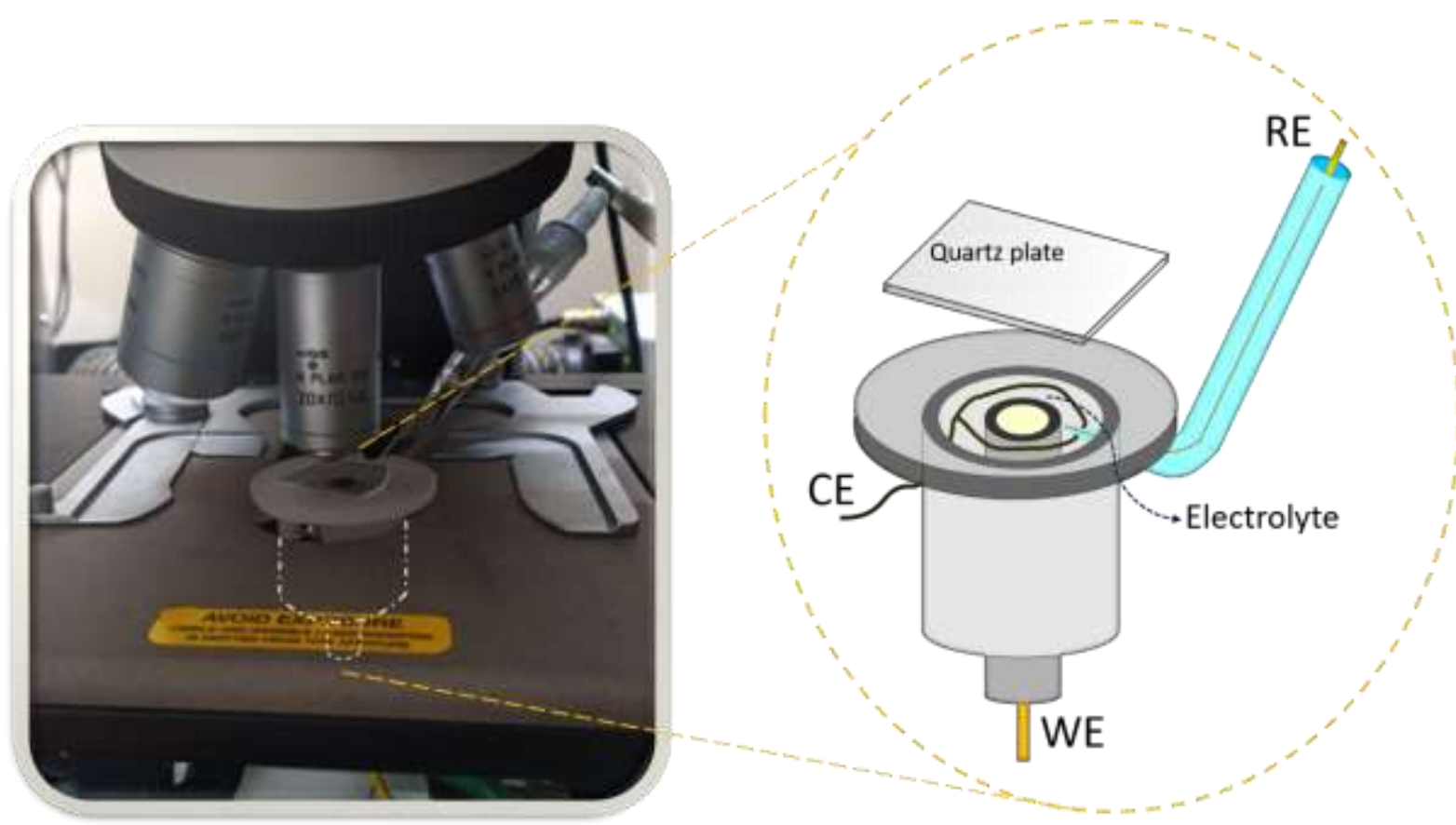
Figure S2. Indigenous three-electrode spectroelectrochemical cell for confocal microprobe Raman spectrometer.

In order to record in-situ time series Raman spectrum, an indigenous spectroelectrochemical cell was designed and fabricated. It is a conventional three-electrode setup primarily designed in an upside-down configuration with respect to the working electrode as shown in Figure S2. This spectroelectrochemical cell was designed to fit with most of the commercial GC electrodes. High-density polypropylene (HD-PP) was used for fabrication to ensure better chemical stability and durability. A square, $0.5 \mathrm{~mm}$ thick quartz plate was used as a transparent window. The working distance of the $20 \mathrm{x}$ objective lens is $7 \mathrm{~mm}$. However, we have designed the cell for a working distance as low as $3 \mathrm{~mm}$ (including a quartz window) to enhance the signal to noise ratio. Two apertures that suits for reference and counter electrode were made at the sides of the cell. A luggin capillary with a thin platinum wire tip was filled with saturated $\mathrm{KCl}$ and a commercial $\mathrm{Ag} / \mathrm{AgCl}$ reference electrode was inserted. This luggin capillary was designed with an inclination of 90 degrees which is suitable to place the reference electrode much close to the working electrode. Ring platinum wire was used as a counter electrode and placed with an electrical contact protruding to the external side. The inside chamber was designed to hold electrolyte total volume of $2 \mathrm{ml}$ which makes a thin layer (approx. $2 \mathrm{~mm}$ ) of electrolyte over the working electrode. The potentiostat was connected to the three electrodes using alligator clips.

\section{ESI 4: Raman spectrum of Nile Blue A powder}

The Raman spectrum of bulk Nile Blue A powder was recorded using a $514 \mathrm{~nm}$ laser with 10 s integration time. Prior to the experiment, the Nile Blue A powder was made into a thin tightly packed film on a glass plate. The obtained Raman modes are decoded using previous reports ${ }^{1,5-6}$ and are listed in table $\mathrm{S} 1$. 


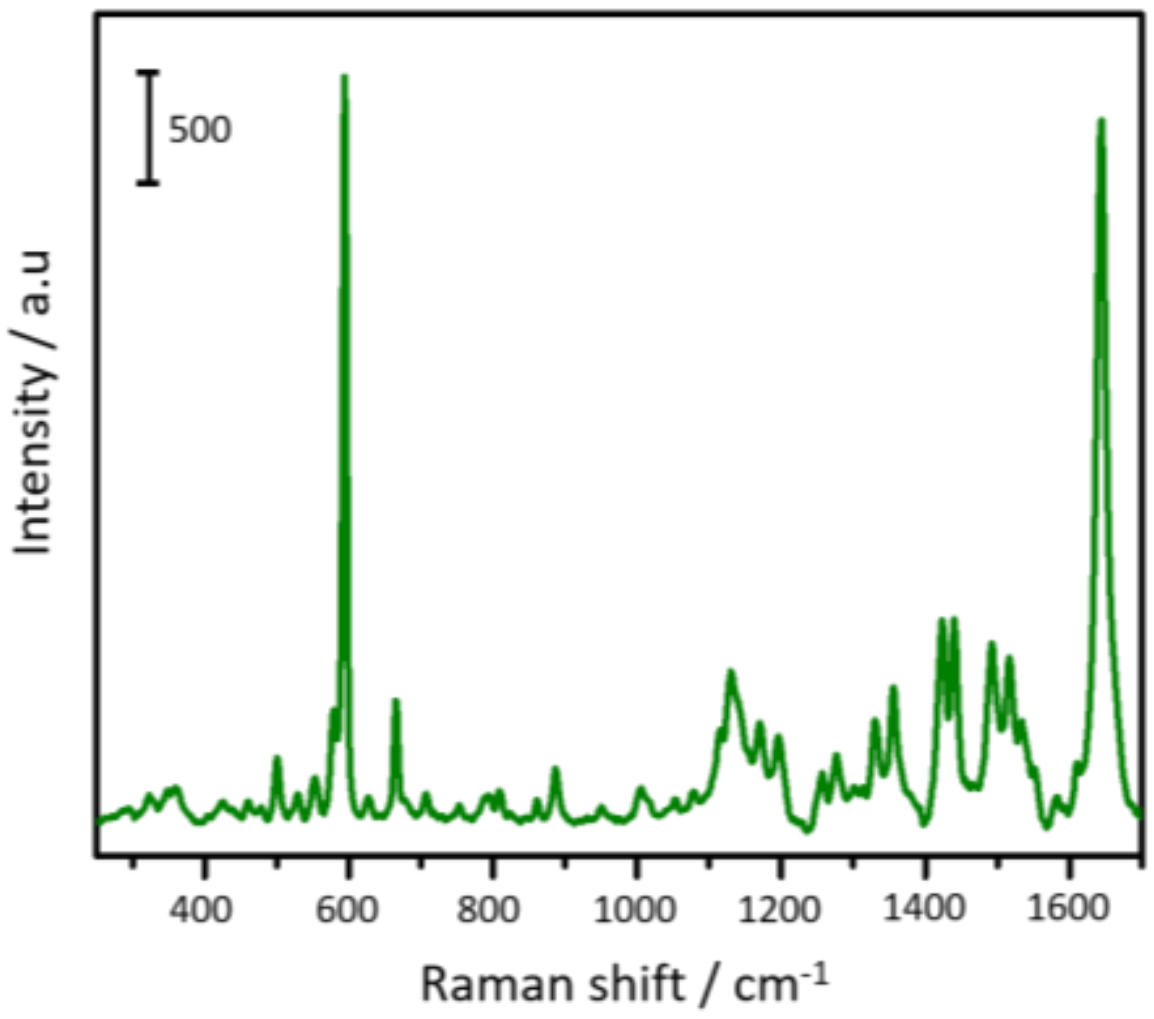

Figure S3. Raman spectrum of Nile Blue A powder.

Table S1: Raman mode assignments for Nile Blue A ${ }^{1,5-7}$.

\begin{tabular}{|c|c|}
\hline Peak position $\left(\mathbf{c m}^{-\mathbf{1}}\right)$ & Band assignments \\
\hline 480 & para benzene ring (I\&II) \\
\hline 591 & in-plane deformation of the heterocyclic ring II \\
\hline 665 & $v_{\text {as }}(\mathrm{C} 2-\mathrm{C} 1-\mathrm{C} 6)$ \\
\hline 708 & skeletal stretching vibrations of tetracylic backbone \\
\hline 750 & $v(\mathrm{~N}-\mathrm{H}),(\mathrm{CH})$ deformation \\
\hline 845 & $v(\mathrm{~N}-\mathrm{H}), v(\mathrm{C}-\mathrm{C})$ \\
\hline 985 & surface-confined dimers and oligomers \\
\hline 1076 & $v(\mathrm{C}-\mathrm{C}), v(\mathrm{C}-\mathrm{N}), v(\mathrm{C}-\mathrm{O})$ \\
\hline
\end{tabular}




\begin{tabular}{|c|c|}
\hline 1147 & $v_{\text {as }}(\mathrm{C} 5-\mathrm{N} 10-\mathrm{C} 9)$ \\
\hline 1196 & $v_{\mathrm{as}}(\mathrm{C} 5-\mathrm{N} 10-\mathrm{C} 9)$ \\
\hline 1360 & $v_{\mathrm{as}}(\mathrm{C} 5-\mathrm{N} 10-\mathrm{C} 9)$ \\
\hline 1400 & $v(\mathrm{C} 13-\mathrm{C} 12) \& v(\mathrm{C} 12-\mathrm{N} 24)$ \\
\hline 1435 & $v_{\mathrm{as}}(\mathrm{C} 5-\mathrm{N} 10-\mathrm{C} 9)$ \\
\hline 1494 & $v(\mathrm{C} 5-\mathrm{N} 10)$ \\
\hline 1541 & $v(\mathrm{C} 5-\mathrm{N} 10)$ \\
\hline 1586 & $v(\mathrm{C}=\mathrm{C})$ \\
\hline 1625 & $\beta(\mathrm{N}-\mathrm{H})$ primary amines \\
\hline 1644 & $\mathrm{NH}$ scissoring \\
\hline
\end{tabular}

$v-$ stretching vibration; $v_{\text {as }}-$ asymmetric stretching vibration; $\beta$ - bending.

\section{ESI 5: Differential spectral data}
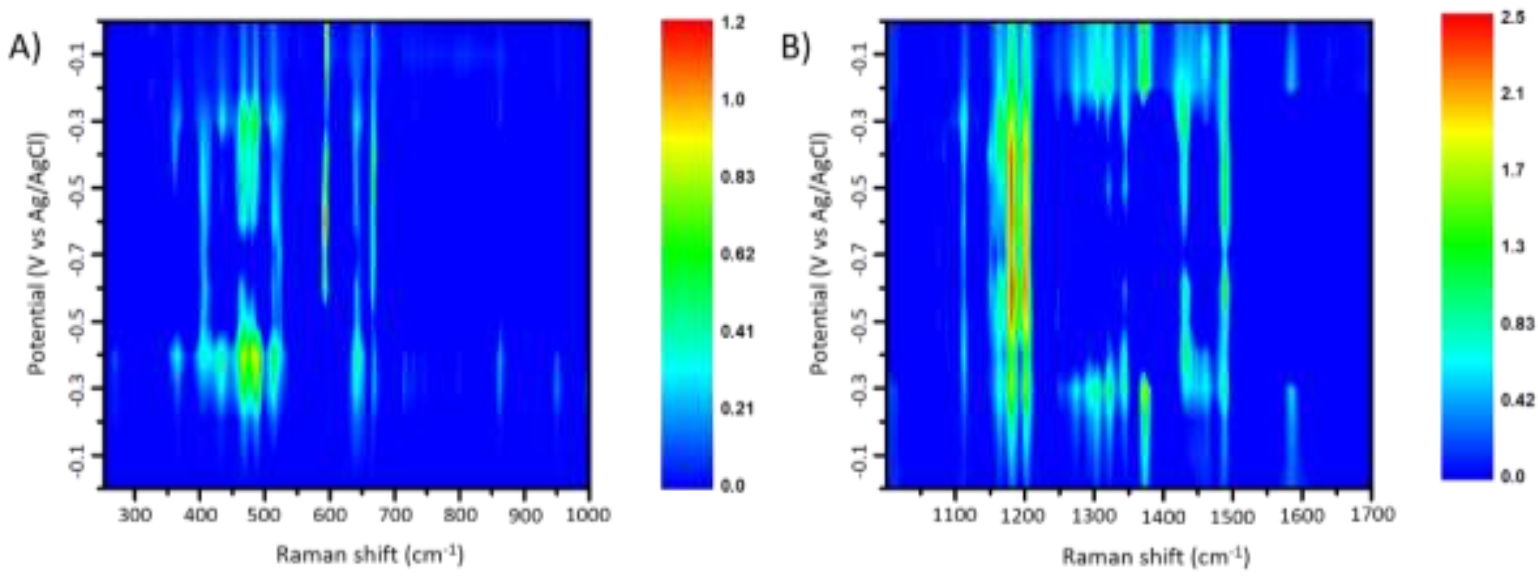

Figure S4. Differential contour map of normalized SERS and SHINERS spectra of NBA on the respective electrodes as a function of applied potential. The portions of the spectra are normalized with respect to the intensity of the modes at (A) $665 \mathrm{~cm}^{-1}$ and (B) $1075 \mathrm{~cm}^{-1}$.

The peaks suppressed by the selective enhancement of few modes in the SERS spectra can be obtained by subtracting the normalized SERS from SHINERS spectra. It is important to note 
that Figure S4 is not a differential contour map. The negative intensities are purposefully ignored to map only the modes suppressed in SERS. It is clearly seen that two modes have been strongly suppressed around $1200 \mathrm{~cm}^{-1}$ due to the selective strengthening of the modes at 1586 and $1644 \mathrm{~cm}^{-1}$.

ESI 6. Reversibility of the electrochemical reaction
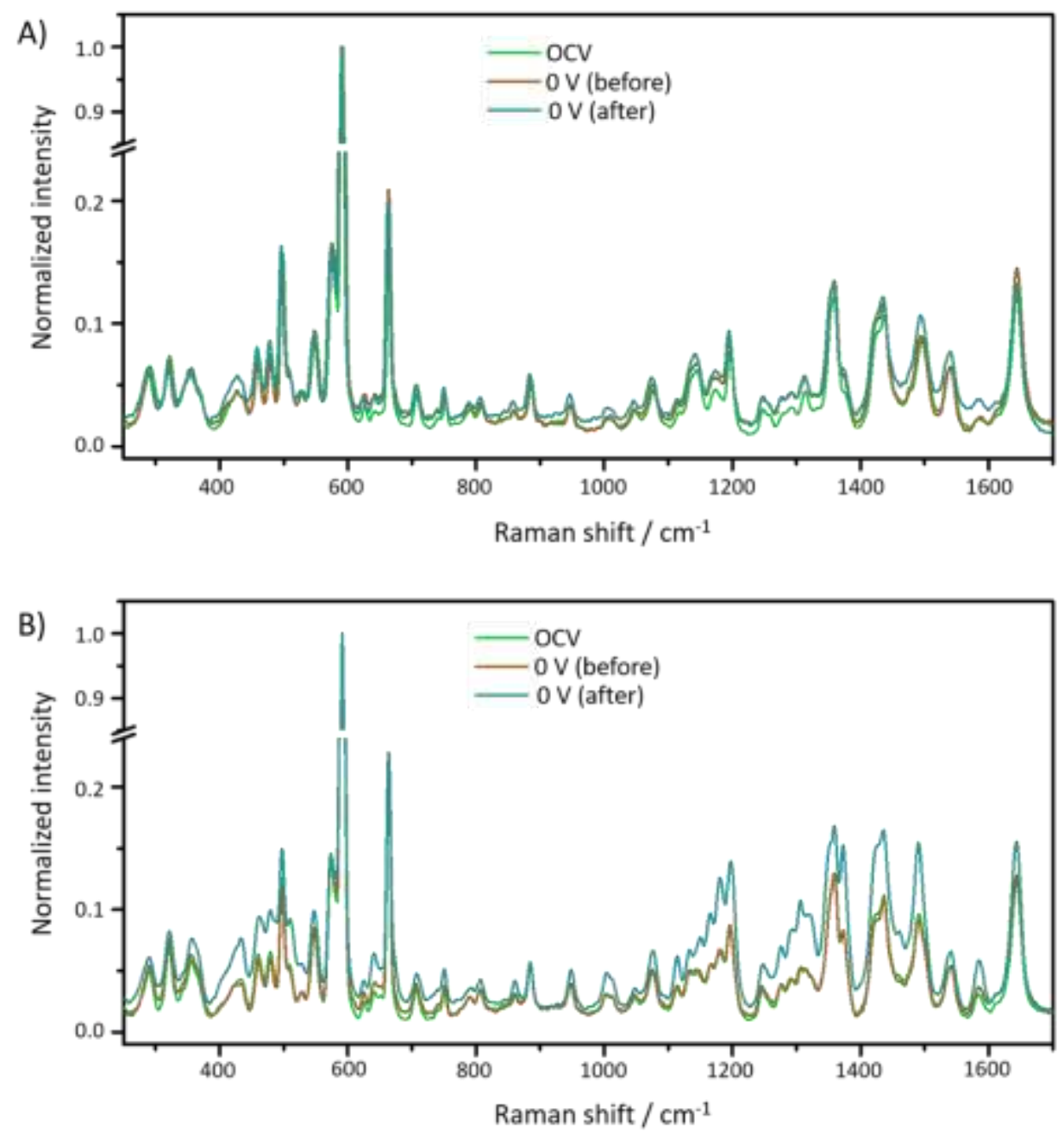

Figure S5. Raman spectrum of Nile Blue A before and after the reaction on (A) SERS and (B) SHINERS electrodes.

The reversibility of the redox reaction of Nile Blue A on SERS and SHINERS electrodes (Figure S5, parts A and B respectively) has been determined by comparing the Raman 
spectrum before and after the reaction. The modes at 1196 and shoulder of $1360 \mathrm{~cm}^{-1}$ have clearly shows that the redox reaction of N10 of NBA on SERS electrodes is more reversible compared to SHINERS electrode. We believe that the stronger interaction with the silver surface holds the molecules whereas the reacted molecules are desorbed and diffuse into the bulk electrolyte in the case of the GCE surface. This may affect the reversibility leading to the presence of reduces species in the electrolyte.

\section{ESI 7. References}

(1) Zong, C.; Chen, C.-J.; Zhang, M.; Wu, D.-Y.; Ren, B. Transient Electrochemical Surface-Enhanced Raman Spectroscopy: A Millisecond Time-Resolved Study of an Electrochemical Redox Process. Journal of the American Chemical Society 2015, 137 (36), 11768-11774.

(2) Ni, F.; Feng, H.; Gorton, L.; Cotton, T. M. Electrochemical and SERS studies of chemically modified electrodes: Nile Blue A, a mediator for NADH oxidation. Langmuir 1990, 6 (1), 66-73.

(3) Mulfinger, L.; Solomon, S. D.; Bahadory, M.; Jeyarajasingam, A. V.; Rutkowsky, S. A.; Boritz, C. Synthesis and Study of Silver Nanoparticles. Journal of Chemical Education 2007, $84(2), 322$.

(4) Saint-Cricq, P.; Wang, J.; Sugawara-Narutaki, A.; Shimojima, A.; Okubo, T. A new synthesis of well-dispersed, core-shell Ag@ $\mathrm{SiO} 2$ mesoporous nanoparticles using amino acids and sugars. Journal of Materials Chemistry B 2013, 1 (19), 2451-2454.

(5) Colthup, N. B. Spectra-Structure Correlations in the Infra-Red Region. J. Opt. Soc. Am. 1950, 40 (6), 397-400.

(6) Mazeikiene, R.; Niaura, G.; Eicher-Lorka, O.; Malinauskas, A. Raman spectroelectrochemical study of redox dye Nile blue adsorbed or electropolymerised at a gold electrode. Chemija 2019, 30 (2), 78-88.

(7) Gong, X.; Liao, X.; Li, Y.; Cao, H.; Zhao, Y.; Li, H.; Cassidy, D. P. Sensitive detection of polycyclic aromatic hydrocarbons with gold colloid coupled chloride ion SERS sensor. Analyst 2019, 144 (22), 6698-6705. 